\title{
Occupational health impacts on the child waste-pickers of Dhaka City
}

\author{
S. Parveen ${ }^{1} \&$ I. M. Faisal ${ }^{2}$ \\ ${ }^{1}$ State University of Bangladesh, Bangladesh \\ ${ }^{2}$ SouthAsia Enterprise Development Facility, Bangladesh
}

\begin{abstract}
This paper examines the occupational health and safety problems faced by the child waste-pickers of Dhaka City. An extensive field survey and physical examinations of the waste-pickers have been used to collect the necessary primary data. The paper tracks down the health problems to their roots with the help of an impact-pathway based analysis. The study finds that the most prevalent types of occupational risks include: bites from insects and rats, cuts and bruises, skin disease, respiratory and gastro-intestinal tract problems, eye irritation, body aches, general weakness, and frequent fever. In order to understand the type and extent of the health and safety risks faced by the waste-pickers compared to non-waste picking children with similar socio-economic and environmental profiles, a comparative epidemiological analysis was carried out using exposed and control groups. It has been found that in terms of point and period prevalence rates, waste-pickers suffer significantly more than the control-group children. Using the linear multiple regression technique, the study further finds that the link between point/period morbidity indices and the risk factor (waste-picking) is a strong one as indicated by the associated t-statistic and overall performance of the models. A number of confounding factors also seem to influence the prevalence of health problems. The regression models indicate that health problems decrease with age, increase with family size, decrease with monthly expenditure, and girls tend to suffer more compared to boys.
\end{abstract}

Keywords: solid waste, health impact, risk factor, confounding factor, prevalence rate, morbidity index. 


\section{Introduction}

Everyday, some 4000-4500 tons of solid waste is generated in Dhaka City by its 10 million inhabitants. About half of this waste is collected by the Dhaka City Corporation (DCC) and disposed at the central landfill site at Matuail. The rest are dumped in open fields, ditches and along street sides creating a major civic health problem. The situation is made worse by fact that the there is no separate system of collection and disposal for clinical and industrial waste in the city - all the hazardous clinical and industrial wastes are dumped in the same municipal bins used for household waste disposal; eventually most of the hazardous wastes also end up in the landfill site.

In this backdrop, what is perhaps the most serious health concern is that there are a few thousand human scavengers in the city, who collect reusable and recyclable materials from garbage bins and landfill sites. A preliminary survey indicates that nearly $50 \%$ of these waste pickers are children under the age of 15 , and about half of them are girls. At the landfill site, they work from dawn to dusk and sell whatever they can salvage (glass, metal, plastic, paper, animal bones) to 'Bhangaries' (traders) at a nominal price. They earn around Taka 40 to 60 (US\$ 0.6 to 0.9 ) a day that may constitute $20 \%-30 \%$ of their family income. As noted by Rouse and Ali [1], 'they enjoy little (if any) access to health services, education or legal aid of any form. In addition, they are perceived as having very low status in society and are strongly associated with criminals.'

Due to such marginal and impoverished social status, these child-workers are being compelled to work in the most unhygienic conditions without any protective measures whatsoever. Even the basic amenities such as water and sanitation are not available to them - there is only one tube well in the entire Matuail area and no sanitary toilet at the site. There is no shelter where the waste pickers could rest, or take refuge when the weather turned unbearable due to intense heat or torrential rain. This is the level of negligence and deprivation endured by the child waste pickers of Dhaka.

As a result of such exposure and negligence, the waste pickers frequently suffer from acute and chronic illnesses and injuries. This study will develop an indepth understanding of these health problems from an epidemiologfical perspective. Specifically, the study will estimate the point and period prevalence rates of the health problems through a comparative cross sectional study, and investigate the association between the health problems with the risk and confounding factors (physical, socio-economic, environmental).

\section{Materials and method}

\subsection{Study design and data collection}

During literature survey, no study could be identified (done in Bangladesh or elsewhere) that directly dealt with the health issues faced by urban waste pickers from epidemiological point of view. At the study design level, the paper by Dolk et al. [2] was found to be informative - it discusses methodological issues related 
to epidemiological assessment of health risks of waste management activities and offers advices on how to avoid some common pitfalls.

This study is primarily based on data and information collected through structured questionnaire survey, interview and physical examination of the respondents. Secondary information from various reports and published sources has also been used as appropriate.

\subsection{Sample design}

The paper is based on a comparative epidemiological study that used two study groups - exposed (waste pickers) and control (non-waste pickers from a different neighbourhood with similar socio-economic and environmental profiles). Each study group was designed as per the stratified random sampling method, where the strata constituted groups of waste pickers of different age and sex. Both groups comprised of 75 randomly selected children aged between six and fifteen; the exposed group was surveyed first and then the control group sample was designed in conformity with the exposed group.

Table 1 shows the major socioeconomic and environmental parameters for the two study groups. As seen from table 1, most of the parameter values are very similar for both groups except for the average years of schooling - fewer children from the exposed group had formal schooling (they could not afford to forego the potential income from waste picking) compared to the children from the control group.

Table 1: $\quad$ Comparative parameters of the study groups.

\begin{tabular}{l|c|c}
\hline Attribute & Exposed & Control \\
\hline Sample size & 75 & 75 \\
Male: female & $1: 1$ & $1: 1.2$ \\
Average age & 11 & 12 \\
Avg. years of schooling & 1 & 4 \\
Family size & 6 & 5 \\
Monthly expenditure (Taka) & 4,527 & 4,779 \\
Access to safe water (\%) & $100 \%$ & $100 \%$ \\
Sanitary latrine at home (\%) & $83 \%$ & $88 \%$ \\
\hline
\end{tabular}

\subsection{Descriptive statistics}

Both statistical summaries and descriptive epidemiological parameters have been used in this study to identify and analyze the type and extent of various health and safety risks faced by the respondents.

This study uses point and period prevalence rates as the primary epidemiological indicators. Point prevalence gives a snapshot of the burden of disease at the time of the survey, but it misses out acutely ill individuals unless special care is taken to include them in the sample. Period prevalence rate 
combines the concept of incidence rate and point prevalence, and is particularly useful in testing the burden of episodic, recurrent and seasonal diseases (Bhopal et al. [3]). These rates are defined as follows:

$$
\begin{aligned}
& \text { Point prevalence rate }=\left(\begin{array}{l}
\text { All cases of the factor at time } t) \\
\qquad(\text { Population at risk at time } t)
\end{array}\right. \\
& \begin{array}{r}
\text { Period prevalence rate }=(\text { All old and new cases of the factor } \\
\text { over a time period }) \\
\div \text { (Average population at risk during the same period })
\end{array}
\end{aligned}
$$

The length of the time period used for estimating period prevalence rate was decided to be six months after some pre-testing of the questionnaire as the respondents could not reliably recollect events that took place more than six months ago.

\subsection{Analysis of association}

This study estimates the strength of association between point and period morbidity indices and associated risk and confounding factors using a multiple linear regression model. The morbidity indices have been calculated as the cumulative frequency of all health related problems as reported by the respondents. Dichotomous variables (dummy variables) have been used to incorporate the risk factor, and some of the independent variables, e.g., gender of the respondent, status of immunization, access to safe water and so on. The general form of the linear regression model is given by eqn. (3).

$$
\begin{aligned}
y_{\mathrm{k}}=c+x_{1, \mathrm{k}}+x_{2, \mathrm{k}}+\ldots+x_{\mathrm{n}, \mathrm{k}}+\varepsilon_{\mathrm{k}} & \\
\text { where, } y_{\mathrm{k}} & =\text { dependent variable (morbidity index) } \\
x_{\mathrm{i}, \mathrm{k}} & =\mathrm{i}^{\text {th }} \text { independent variable (risk factor, confounders) } \\
\varepsilon_{\mathrm{k}} & =\text { residual for the } \mathrm{k}^{\text {th }} \text { observation }
\end{aligned}
$$

Criteria for selection of variables and functional forms for regression analysis can be found in standard texts such as Kleinbaum et al. [4], Draper and Smith [5], and Palta [6].

\section{Environmental health impacts}

\subsection{Health risks}

The present mode of solid waste management by the DCC poses a number of environmental health risks. First, the city does not have separate waste disposal systems for clinical and industrial wastes. Everyday, some 500 hospitals, clinics and pathological laboratories generate 200 tons of waste, about $15 \%$ to $20 \%$ of which are extremely hazardous that include infectious waste, pathological waste, sharps, and a small amount of pharmaceutical and chemical wastes (Rahman 
et al. [7]). Moreover, several thousand industries located within the city (including the 'hot-spots' at Hazaribagh and Tejgaon) generate hazardous solid wastes that contain corrosives, toxic chemicals and heavy metals. Both clinical and industrial wastes are dumped in municipal landfill sites or in open fields and ditches exposing the city residents to unknown health hazards.

Second, about half of the solid waste generated in the city - some 2,250 tons a day- is not collected at all, which may include some medical and industrial wastes. Often, wastes are not collected on time and seen rolling in the streets attracting scavengers and unwanted biota.

Third, the most serious health risks are faced by the human scavengers: around 6000 to 8000 of them work in the streets and at landfill sites as waste pickers. A preliminary survey indicates that nearly $50 \%$ of them are children under the age of fifteen, and about half of them are girls. Due to their marginal and impoverished social status, these child-workers are compelled to work in the most unhygienic conditions without having access to most basic amenities such as drinking water and sanitation at workplace.

\subsection{Most frequent impacts}

The cumulative health impacts of all these threats on the city population are unknown - no study has so far been conducted to scientifically link these risks with health impacts. However, a number of recent studies have examined the occupation health hazards faced by the waste pickers of Dhaka, who worked in the streets or at the Matuail landfill site [8, 9, 10]. Shamsad [9], and Parveen and Faisal [10] have identified stressors (in most cases indicated by the respondents) and sources of the most common health problems faced by the waste pickers as summarized in table 2 (for prevalence rates, see table 3 ). The waste pickers face a whole range of health risks - from minor on-site problems such as insect bite to major health concerns such as bronchitis, hepatitis, and physical injury.

It was found that in most cases, no medication is used or doctor consulted. The waste pickers resort to over-the-counter medicine or take a day-off only if they suffer from grave and debilitating ailments.

\subsection{Point and period prevalence rates}

Parveen and Faisal [10] have further extended these findings by conducting a comparative epidemiological study of the health impacts using 'exposed' and 'control' groups. By comparing point and period prevalence rates for different health problems faced by these groups, they show that the child waste-pickers of Dhaka suffer significantly more compared to the 'non-waste picking' control group (table 3 ). It is evident from table 3 that the child waste-pickers suffered from $30 \%$ more skin problems, $40 \%$ more eye, respiratory and general health problems, $47 \%$ more aches and pains, and 20\% more gastro-intestinal ailments. The difference is even greater if period prevalence rates for skin and eye related problems are compared. The most significant difference is noted for fever $-62 \%$ more waste pickers suffered from some kind of fever during a six-month period prior to this survey compared to the control group. 
Table 2: $\quad$ Impact pathway of common health problems.

\begin{tabular}{lll}
\hline Health problem & Stressor & Source \\
\hline $\begin{array}{l}\text { General health (weakness, } \\
\text { nausea, loss of appetite etc.) }\end{array}$ & Pungent smell & Exposed organic waste \\
\hline Aches and body/joint pain & $\begin{array}{l}\text { Long working hours } \\
\text { without rest }\end{array}$ & Poor work environment \\
\hline Skin disease and allergy & All types of waste & All waste sources \\
\hline Respiratory and eye problems & Dust, fume, smoke & $\begin{array}{l}\text { Burning of plastic, tire, } \\
\text { incineration }\end{array}$ \\
\hline $\begin{array}{l}\text { Gastro-intestinal problems } \\
\text { and worms }\end{array}$ & $\begin{array}{l}\text { Drinking water, dirty } \\
\text { hand or utensils }\end{array}$ & $\begin{array}{l}\text { Lack of sanitation; poor } \\
\text { personal hygiene }\end{array}$ \\
\hline $\begin{array}{l}\text { Cuts and bruises, infection, } \\
\text { physical injury }\end{array}$ & $\begin{array}{l}\text { Sharp / pointed } \\
\text { objects, heavy } \\
\text { machineries }\end{array}$ & $\begin{array}{l}\text { Hospitals and health } \\
\text { centres, households, } \\
\text { landfill machineries }\end{array}$ \\
\hline Pain and inflammation & Insect / mosquito bites & Bare foot/hand \\
\hline $\begin{array}{l}\text { Fever (infection, viral, } \\
\text { malaria, dengue etc.) }\end{array}$ & $\begin{array}{l}\text { Cold, infection, } \\
\text { mosquito bite }\end{array}$ & Poor landfill conditions \\
\hline $\begin{array}{l}\text { TB, bronchitis, hepatitis, } \\
\text { AIDS etc. }\end{array}$ & Clinical waste & $\begin{array}{l}\text { Hospitals and health } \\
\text { centres }\end{array}$ \\
\hline $\begin{array}{l}\text { Sore, metabolic disorders, } \\
\text { cancer }\end{array}$ & $\begin{array}{l}\text { Corrosive, toxic and } \\
\text { radioactive chemicals }\end{array}$ & Industrial or clinical waste \\
\hline
\end{tabular}

\subsection{Influence of the risk and confounding factors}

By employing the multiple regression technique, Parveen and Faisal [10] also show that there are statistically significant associations between the point and period morbidity indices and the risk factor - waste picking. This confirms the generally held view that a significant part of the health problems affecting the waste pickers are due to their hazardous occupation, and the rest of the impacts are outcomes of other socio-economic and environmental factors.

Table 4 shows the statistical associations between the point morbidity index and the confounding and risk factors: age, gender, monthly family expenditure, family size, and group of the respondent. The regression coefficients and $\mathrm{t}$ statistics support a number of important conclusions: (i) the exposed group is more vulnerable to health problems than the control group; (ii) younger children tend to suffer more from health problems compared to older ones; (iii) girls suffer from more health problems compared to boys; (iv) morbidity is positively correlated to family size (crowding factor); and, (v) morbidity is negatively correlated to family expenditure (possible nutritional impact). Originally, access to water and sanitary latrine were included in the regression model but were dropped later on as they came out to be statistically insignificant. In fact, as evident from table 1 that there is little difference between the exposed and control groups in terms of these factors.

The overall goodness of fit of the linear multiple regression model for point morbidity index is satisfactory as indicated by $\mathrm{R}^{2}=0.69$ and $\mathrm{F}=64.42$ for a combined sample size of 150 . 
Table 3: Prevalence of health problems in exposed and control groups.

\begin{tabular}{|c|c|c|c|c|}
\hline \multirow{2}{*}{ Health problem } & \multicolumn{2}{|c|}{ Exposed group } & \multicolumn{2}{|c|}{ Control group } \\
\hline & Point (\%) & Period (\%) & Point (\%) & Period (\%) \\
\hline Weakness & 94.67 & 96.00 & 40.00 & 49.33 \\
\hline Dizziness / nausea & 88.00 & 90.67 & 6.67 & 9.33 \\
\hline Loss of appetite & 85.33 & 88.00 & 30.67 & 36.00 \\
\hline Burning sensation & 86.67 & 88.00 & 10.67 & 10.67 \\
\hline Swelling limbs & 5.33 & 32.00 & 1.33 & 1.33 \\
\hline UTI & 12.00 & 42.67 & 4.00 & 8.00 \\
\hline General health & 96.00 & 97.33 & $\mathbf{5 7 . 3 3}$ & 70.67 \\
\hline Headache & 86.67 & 93.33 & 38.67 & 57.33 \\
\hline Back pain & 68.00 & 82.67 & 10.67 & 13.33 \\
\hline Pain the joint & 73.33 & 82.67 & 8.00 & 12.00 \\
\hline Ache and pain & 92.00 & 94.67 & 45.33 & 69.33 \\
\hline Itching & 49.33 & 73.33 & 18.67 & 25.33 \\
\hline Eczema & 9.33 & 24.00 & 2.67 & 2.67 \\
\hline Scabies & 10.67 & 38.67 & 14.67 & 18.67 \\
\hline Abscess & 2.67 & 56.00 & 0.00 & 0.00 \\
\hline Lice & 80.00 & 81.33 & 30.67 & 32.00 \\
\hline Skin & 82.67 & 97.33 & 52.00 & 58.67 \\
\hline Cough & 66.67 & 82.67 & 32.00 & 42.67 \\
\hline Breathing problem & 36.00 & 60.00 & 5.33 & 6.67 \\
\hline Blood with cough & 2.67 & 4.00 & 2.67 & 2.67 \\
\hline Throat infection & 24.00 & 46.67 & 4.00 & 6.67 \\
\hline Chest pain & 32.00 & 53.33 & 1.33 & 4.00 \\
\hline Oral infection & 29.33 & 49.33 & 1.33 & 1.33 \\
\hline Respiratory & 74.67 & 85.33 & 36.00 & 46.67 \\
\hline Acidity & 72.00 & 81.33 & 22.67 & 32.00 \\
\hline Loose motion \& Vomiting & 62.67 & 76.00 & 32.00 & 37.33 \\
\hline Blood Dysentery & 13.33 & 64.00 & 2.67 & 4.00 \\
\hline Pain in stomach & 62.67 & 76.00 & 18.67 & 29.33 \\
\hline Gastro-intestinal & 74.67 & 85.33 & 56.00 & 74.67 \\
\hline Cuts from sharp objects & 66.67 & 80.33 & 4.00 & 6.67 \\
\hline Injury caused by machines & 0.00 & 1.00 & 0.00 & 0.00 \\
\hline Wound/injury & 66.67 & 80.33 & 4.00 & 6.67 \\
\hline Eye irritation & 34.67 & 53.33 & 6.67 & 10.67 \\
\hline Blurry vision & 18.67 & 25.33 & 1.33 & 1.33 \\
\hline Eye infection & 4.00 & 22.67 & 1.33 & 1.33 \\
\hline Night blindness & 16.00 & 16.00 & 0.00 & 0.00 \\
\hline Eye & 45.33 & 65.33 & 6.67 & 10.67 \\
\hline Fever & 12.00 & 70.67 & 9.33 & 13.33 \\
\hline Fever blister & 0.00 & 4.00 & 0.00 & 0.00 \\
\hline Persistent fever & 6.67 & 9.33 & 6.67 & 8.00 \\
\hline Recurrent fever & 21.33 & 32.00 & 1.33 & 1.33 \\
\hline Fever & 34.67 & 85.33 & 17.33 & 22.67 \\
\hline Ear pain & 6.67 & 24.00 & 8.00 & 10.67 \\
\hline Ear infection & 6.67 & 29.33 & 5.33 & 6.67 \\
\hline Loss of hearing & 1.33 & 1.33 & 2.67 & 2.67 \\
\hline Ear & 9.33 & 33.33 & 12.00 & 16.00 \\
\hline
\end{tabular}


Table 4: Statistical association between point morbidity index and risk/confounding factors.

\begin{tabular}{l|c|c|c|c}
\hline \multirow{2}{*}{ Model variables } & \multicolumn{2}{|c|}{ Coefficients } & \multirow{2}{*}{ t } & \multirow{2}{*}{ Sig. } \\
\cline { 2 - 3 } & $\mathrm{B}$ & Std. Error & & \\
\hline (Constant) & 6.274 & 1.665 & 3.768 & .014 \\
Age & -.334 & .107 & -3.116 & .002 \\
Gender & 1.675 & .564 & 2.970 & .003 \\
Family expenditure & .000 & .000 & -1.841 & .068 \\
Family size & .559 & .218 & 2.562 & .011 \\
Group & 8.681 & .620 & 14.002 & .000 \\
\hline
\end{tabular}

Note: Dependent Variable: Point morbidity index. $\mathrm{R}^{2}=0.691, \mathrm{~F}=64.424, \mathrm{~N}=150$.

A similar linear regression model has been used to test the associations between the period morbidity index and the above mentioned set of dependent variables. Results of this model are shown in table 5. The conclusions from this model are exactly the same as before (it is not entirely surprising as the point morbidity information is embedded within the period morbidity index). Particularly, the 'group' variable is strongly significant and it again indicates that waste picking as an occupation had significant influence on the overall morbidity of the children. In terms of the t-statistics, except for 'group' and 'age', other confounding factors are not significant at $95 \%$ confidence level. This may be due to the fact that period prevalence is based on mental recollection of past morbidity and therefore may not be as accurate as the point prevalence, which was verified on the spot by qualified physicians.

The overall goodness of fit of this model is quite satisfactory as indicated by $\mathrm{R}^{2}=0.735$ and $\mathrm{F}=79.92$ for a combined sample size of 150 .

Table 5: Statistical association between period morbidity index and risk/confounding factors.

\begin{tabular}{l|c|c|c|c}
\hline \multirow{2}{*}{ Model variables } & \multicolumn{2}{|c|}{ Coefficients } & t & \multirow{2}{*}{ Sig. } \\
\cline { 2 - 3 } \cline { 1 - 1 } (Constant) & $\mathrm{B}$ & Std. Error & & \\
Age & 10.135 & 2.160 & 4.692 & .000 \\
Gender & -.402 & .139 & -2.891 & .004 \\
Family expenditure & .333 & .732 & .456 & .649 \\
Family size & .000 & .000 & -1.407 & .161 \\
Group & .344 & .283 & 1.216 & .226 \\
\hline
\end{tabular}

Note: Dependent Variable: Period morbidity index. $\mathrm{R}^{2}=0.735, \mathrm{~F}=79.922, \mathrm{~N}=150$.

\section{Concluding remarks}

This study has identified the most frequently occurring health and safety problems faced by the child waste-pickers of Dhaka City. By comparing the 
statistics of waste pickers with the control group statistics, it has been found that there are significant differences between the point and period morbidity levels of these groups and these differences may be attributed to the hazardous occupation of waste picking.

This problem of health impacts on waste pickers is a much more complex one than it appears on the surface. This is really an outcome of not having an integrated and ecosystem based solid waste management plan for the city. In a recent paper, Faisal and Parveen [11] show how an ecosystem-based approach can be used to analyze the issues from a system perspective and identify a range of intervention options to address the issue in a comprehensive manner. Even then, complete alleviation of environmental health impacts is likely to take a long time; it will require preparing a detailed 'blue print' for action as well as gradual and committed implementation of the same.

\section{Acknowledgement}

This paper is based on an earlier research that was funded by the International Development Research Centre (IDRC), Canada under Ecosystem Approach to Human Health Award. The authors gratefully acknowledge this contribution of IDRC.

\section{References}

[1] Rouse, J., and Ali, M., Waste Pickers in Dhaka, Water, Engineering and Development Center (WECD): Loughborough University, UK. 2001.

[2] Dolk, H., Vrijheid, M., Armstrong, B., Abramsky, L., Bianchi, F., Grane, E., Nelen, V., Robert, E., Scott, J.E.S., Stone, D., \& Tenconi, R., Risk of congenital anomalies near hazardous waste landfill sites in Europe: the EUROHAZCON study. Lancet, 352, pp. 423-427, 1998.

[3] Bhopal, R.S., Phillimore, P., \& Moffat, S., Is living near a coking works harmful to health? J. Epidemiol. Comm. Health, 48, pp. 237-47, 1994.

[4] Kleinbaum, D.G., Kupper, L. L., Muller, K. E., \& Nizam, A., Applied Regression Analysis and Multivariable Methods ( $3^{\text {rd }}$ ed.), Brooks Cole, 1997.

[5] Draper, N. R., \& Simth, H., Applied Regression Analysis (3 ${ }^{\text {rd }}$ ed.). John Wiley \& Sons: New York, 1998.

[6] Palta, M., Quantitative Methods in Population Health: Extension of Ordinary Regression, John Wiley \& Sons: New York, 2003.

[7] Rahman, M. H., Ahmed, S. N., and Ullah, M. S., A study on hospital waste management in Dhaka City, Proc. Of the 25th WECD Conference, Integrated Development for Water Supply and Sanitation: Addis Ababa, 1999.

[8] Khanam, K. A., Socio-Demographic Characteristics and Morbidity Pattern of Waste Pickers of Dhaka City. National Institute of Preventive and Social Medicine (NIPSOM), Dhaka, 2000. 
[9] Shamshad, R., Occupational Health Hazard of the Scavenger Children in Matuail Landfill Site, Unpublished Thesis, Department of Environmental Studies, North South University, Dhaka, Bangladesh, 2003.

[10] Parveen, S. \& Faisal, I. M., An Epidemiological Investigation of Health Impacts on the Child Waste-Pickers of Dhaka City, Unpublished working paper, State University of Bangladesh, Dhaka, 2005.

[11] Faisal, I. M., \& Parveen, S. Alleviation of Environmental Health Impacts through Ecosystem Approach - A Case Study on Solid Waste Management in Dhaka City, paper presented at Sustainable Planning 2005, Bologna, Italy, September 12-14, 2005. 